\title{
Outcomes of endometrial-polyp treatment with hysteroscopy in operating room
}

\author{
D. Andía Ortiz • A. Gorostiaga Ruiz-Garma • \\ I. Villegas Guisasola • F. Mozo-Rosales Fano • \\ V. San Román Sigler • A. Escobar Martinez
}

Received: 19 May 2007 / Accepted: 10 July 2007 / Published online: 1 September 2007

(C) Springer-Verlag 2007

\begin{abstract}
To assess the results of using a resectoscope in the hysteroscopic resection of endometrial polyps that were previously diagnosed by office hysteroscopy and to demonstrate the necessity of extraction for histological study. A prospective long-term follow-up study (level of evidence II-2). University Hospital. 303 women presenting a hysteroscopic image of an endometrial polyp. Interventions: Office hysteroscopy, hysteroscopic resection of polyps by means of a resectoscope and an anatomopathological study of the polyps. Statistical analysis was performed. 303 diagnosed endometrial polyp formations were resected by means of hysteroscopy during surgery. In all cases, biopsies of the uterine cavity or of the polyp were negative. Resection of the polyps with hysteroscopy in the operating room using a resectoscope proved to be a safe technique. The anatomopathological study of the polyps showed hyperplasia with atypias in 10 cases (3.3\%) and endometrial cancer in 9 women (3.0\%). Our study data suggest that endometrial polyps should be resected because they may harbor malignant or premalignant lesions. Hysteroscopic surgery is recommended for its simplicity and scant complications.
\end{abstract}

D. Andía Ortiz $\cdot$ A. Gorostiaga Ruiz-Garma

I. Villegas Guisasola • F. Mozo-Rosales Fano •

V. San Román Sigler

Department of Obstetrics and Gynecology, Basurto Hospital,

Basque Country University,

Bilbao, Spain

A. Escobar Martinez

Investigation Unit, Basurto Hospital, Basque Country University,

Bilbao, Spain

D. Andía Ortiz $(\square)$

Servicio de Obstetricia y Ginecología, Hospital de Basurto, Avenida de Montevideo $\mathrm{N}^{\circ} 18$,

48013 Bilbao, Spain

e-mail: Dandia@hbas.osakidetza.net
Keywords Hysteroscopy · Endometrial polyp · Endometrial cancer $\cdot$ Hysteroscopic resection

\section{Introduction}

As a diagnostic technique, hysteroscopy is a highly reliable and sensitive tool compared with hysterectomy in terms of anatamopathological findings [1]. Furthermore, it is considered a gold standard for diagnosing women with abnormal uterine bleeding (AUB). Furthermore, endometrial polyps are found to be the most frequent cause of AUB. These are the factors that contribute towards making the diagnosis of endometrial polyps more and more frequent in our setting.

The importance of endometrial polyps centers on two aspects. First is their relationship to endometrial carcinoma, as already described in earlier publications [2]. This relationship may be due to the possibility of the polyp becoming malignant or because a false-negative result occurs when a carcinoma at the base or at the end of a polyp is not detected. The second aspect of importance relates to endometrial polyps as the cause of AUB.

When polyps are small to medium in size but pedicled, their section by means of scissors and their extraction during office hysteroscopy is advocated ("see and treat"). Thus, by a simple office procedure, continuous flow hysteroscopy, precise diagnosis and treatment are achieved. In addition, the extracted material is sent to the laboratory for a histological study. This allows for the diagnosis of other conditions such as hyperplasias, which have been proved to occur more frequently in polyp biopsies [3] and for possible malignancy of a polyp to be ruled out. However, some authors have described spontaneous regression rates over $50 \%$ for small polyps [4]. Small polyps can 
be removed during office hysteroscopy, while large polyps are difficult to remove during the office hysteroscopy.

Two treatments have been accepted for polyps that are larger in size or when their extraction may be difficult. One is to perform an hysteroscopy-directed biopsy on a polyp fragment and to monitor the patient, providing there is no history of bleeding. The other is to adopt an active approach that consists of resectoscopic resection of the polyp in the operating room (operating room hysteroscopy). The latter option has been widely defended, firstly because resecting the polyp would probably prevent AUB, and secondly, because the polyp may present a malignant transformation at its base or tip that would not be diagnosed unless it were resected.

The purpose of this study is to analyze the results of our resection of endometrial polyps and to evaluate anatomopathological diagnoses. We discuss the convenience or inconvenience of resecting polyps in the light of those results.

\section{Materials and methods}

This paper reports an observational prospective study carried out by the gynecological department at the Basurto Hospital in Bilbao between January 1998 and February 2004. It includes 303 patients whose cases suggested endometrial polyp, which could not be removed by office hysteroscopy. The patients came from health clinics or gynecological emergency centers and were sent to the office hysteroscopy unit-located in the hospital's outpatient department - due to suspected endometrial pathology. They were operated on in the surgery room to resect the polyp and to perform an anatomopathological study.

The patients were considered to be menopausal if their period had been missing for at least 12 months. We use the terms abnormal uterine bleeding (AUB) and postmenopausal bleeding (PMB). Treatments with tamoxifen refer to women with breast cancer dosed with $20 \mathrm{mg}$ of tamoxifen daily.An office continuous-flow hysteroscopy was performed on all the women. We used a rigid diagnostic hysteroscopy telescope, $4 \mathrm{~mm}, 30^{\circ}$ wide angle, sheath $5.5 \mathrm{~mm}$, continuous flow (Olympus Winter IBE, Hamburg, Germany). The distension medium was physiological serum fluid. During this procedure, a biopsy of the polyp was performed directly with 5 French flexible scissors and grasping forceps.

When the polyp was small, excision was performed at the time of the office hysteroscopy. If the polyp proved to be malignant at the initial biopsy, the case was excluded from the study. Only those patients who had larger or more widely spread polyps that required resectoscopy for extirpation (303 patients) were included in our study.
The operation was explained to the women, and they were asked to sign their informed consent to the operation. All of these patients were included in the study. Therefore, the study consisted of women who had an endometrial polyp extracted by means of a resectoscopy.

After a preoperative assessment, the patients went to the hospital. In the gynecological operating room, with spinal anesthesia, dilatation was achieved $0.5 \mathrm{~mm}$ at a time with Hegar dilators. A 9-mm sheath was placed (27 French) and coupled to the resector and the optical lens, a 4-mm, $12^{\circ}$ Olympus Winter IBE (Hamburg, Germany). We used a 27 French resection electrode angled loop. The fluid used for distension was glycine, in 3-1 bags, applied with an Olympus Uteromat hysteroscopy irrigation pump. Videoendoscopic equipment was used, coupling a microcamera to the optical lens. The electric generator used was Valleylab Force 40 (Pfizer, Boulder, CO, USA). We used monopolar cut mode, 100 watts power.

The hysteroscopies in the operating room were always performed by the same two gynecologists.

Data on the operation, type of anesthesia used, type of patient admission, estimated surgery duration, and the consumption and loss of glycine were obtained. Complications were also recorded, including uterine perforations during dilatation or with the loop and cervical tears (usually caused by applying traction with the Pozzi forceps). Both were considered a complication when some kind of suture was required. The third kind of complication was hemorrhage, defined as bleeding more than usual that required placing an intrauterine Foley catheter for a few hours.

Data were entered into a database with the program Epi-info and analyzed using SPSS v.11.0. For the analysis of parametric variables, we used the varianza analysis with the Scheffé test and for the analysis of nonparametric variables, we used the chi-squared test.

Patients used a non-admission bed at the outpatient surgery unit and were discharged after a few hours. The patients whose final diagnosis was an endometrial polyp needed no additional procedure in the follow-up interval. When the final diagnosis was a hyperplasia with atypia, a hysterectomy was performed, however if the diagnosis was endometrial cancer, the gynecology oncologic commitee in our hospital selected the final treatment. In all cases of endometrial cancer, hysterectomy and lymphadenectomy were performed.

\section{Results}

The results of surgical hysteroscopies accomplished in our unit over a 6-year period were analyzed.

Mean age was higher in women with endometrial cancer (67.3 years old) than in women with a polyp (54.2 years 
old) $(P<0.001)$ or hyperplasia with atypias (60.7 years old). The percentage of postmenopausal patients was also higher among those with endometrial cancer than polyp carriers and in the women who presented hyperplasias with atypias. See Table 1.

In premenopausal women, the mean size of the polyp was $3 \mathrm{~cm}(1-6 \mathrm{~cm})$ and of the hyperplasias with atypias was $3 \mathrm{~cm}(2-4 \mathrm{~cm})$, whereas the size of endometrial carcinomas was $3.5 \mathrm{~cm}(3-5 \mathrm{~cm})$. In postmenopausal women, the size was $3.7 \mathrm{~cm}(1-7 \mathrm{~cm})$ in polyps, $5 \mathrm{~cm}$ $(2-7 \mathrm{~cm})$ in atypical hyperplasias, and $4.2 \mathrm{~cm}(2-6 \mathrm{~cm})$ in endometrial cancers.

The biopsies prior to surgery were negative in all cases and were reported as functional or atrophic, as a benign polyp, as hyperplasia without atypias, or as insufficient material for a histological diagnosis.

The reason these patients were sent to consultation was premenopausal or postmenopausal bleeding in the case of polyps. When the result was hyperplasias with atypias or endometrial cancer, the principal reason for sending the patients to our unit was to study an abnormal vaginal ultrasound image of the uterine cavity. That means that the first reason to indicate hysteroscopy in these women was the abnormal data of vaginal ultrasound (image compatible with a polyp). In certain cases, the consultation was made because the patients had breast cancer and were being treated with tamoxifen. See Table 2.

We can tell from analyzing the data for the hysteroscopic surgery that in most cases spinal anesthesia was used. Likewise, nearly all of the patients entered the outpatient surgery unit. In 13 patients with endometrial polyps and one patient with endometrial cancer, conventional hospital admission was necessary. Six of these patients had an associated medical problem, and the others were going to have another operation aside from the hysteroscopy: three for urinary stress incontinence, two for a laparoscopy for sterilization, and three needed surgery for ovarian benign procedures.

The loss of glycine was $345 \mathrm{ml}$ in the patients with hyperplasia with atypias, $289 \mathrm{ml}$ in women with endometrial cancer, and $179.5 \mathrm{ml}$ for benign polyps.

Table 1 Population characteristics

\begin{tabular}{llll}
\hline & Polyps $(n=284)$ & $\begin{array}{l}\text { Hyperplasia with } \\
\text { atypias }(n=10)\end{array}$ & $\begin{array}{l}\text { Endometrial } \\
\text { cancer }(n=9)\end{array}$ \\
\hline Age & $54.2 \pm 10.7^{*}$ & $60.7 \pm 13.5$ & $67.3 \pm 15.1^{*}$ \\
Parity & $2.34 \pm 3.6$ & $3.3 \pm 1.3$ & $3.1 \pm 2.3$ \\
Menopausal & $61.3 \%$ & $80 \%$ & $88.9 \%$ \\
\hline
\end{tabular}

*The comparative data are not statistically significant, except for the age difference in the cases with polyps and the cases with endometrial cancer, where $P<0.001$
Table 2 Signs and symptoms: reasons for the consultation

\begin{tabular}{llll}
\hline & $\begin{array}{l}\text { Polyps } \\
(n=284)\end{array}$ & $\begin{array}{l}\text { Hyperplasia } \\
\text { with atypias } \\
(n=10)\end{array}$ & $\begin{array}{l}\text { Endometrial } \\
\text { cancer } \\
(n=9)\end{array}$ \\
\hline $\begin{array}{l}\text { Premenopausal AUB } \\
\begin{array}{l}\text { Postmenopausal } \\
\text { bleeding }\end{array}\end{array}$ & $\begin{array}{l}23.6 \% \\
42.3 \%\end{array}$ & - & - \\
$\begin{array}{l}\text { Heavy and prolonged } \\
\text { menstrual bleeding }\end{array}$ & $7.4 \%$ & - & $44.4 \%$ \\
$\begin{array}{l}\text { Abnormal US } \\
\text { Treated with } \\
\text { tamoxifen }\end{array}$ & $17.3 \%$ & $40 \%$ & - \\
Other causes & $8.8 \%$ & $10 \%$ & $33.3 \%$ \\
\hline
\end{tabular}

The comparative data of the causes show no statistically significant differences. $A U B$ Abnormal uterine bleeding, US ultrasound

Complications were rare. There were no complications when the end diagnosis was hyperplasia with atypias or endometrial cancer. For polyps, we had three cases of cervical tears, three cases of uterine perforation, and two cases of hemorrhage. There were no serious complications, and further surgery was not necessary in any case. See Table 3.

\section{Discussion}

Although the trend in gynecological practice is to resect polyps, there has been no united opinion on this option. Professionals fail to agree on how it should be performed [5]. However, it seems to have been demonstrated that hysteroscopy-controlled extraction of polyps is superior to other techniques [6], and that transcervical resection is considered the gold standard for treating endometrial polyps [7].

The prevalence of polyps in asymptomatic premenopausal women is estimated to be $10 \%$. In patients with abnormal uterine hemorrhage, it is between 13 and 50\% [8], and in asymptomatic patients who take tamoxifen, 29.4\% [9]. The risk increases threefold in women who take tibolone [10], and polyps have even been associated with endometriosis [11].

The color Doppler allows the selection of certain patients for conservative treatment of endometrial polyps [12]. In addition, low rates of resistance have been related to the degree of atypia and were found to be highly predictive [13]. Another study could not identify any distinct hysteroscopic feature of malignancy, but all malignant polyps removed by operative hysteroscopic were symptomatic [14]. However, a study that evaluated the patient's age, the polyp's volume, whether it bled, the resistance index 
Table 3 Surgical characteristics

\begin{tabular}{llll}
\hline & Polyps $(n=284)$ & Hyperplasia with atypias $(n=10)$ & Endometrial cancer $(n=9)$ \\
\hline Intradural anesthesia $(\%, 95 \% \mathrm{CI})$ & $96.8(94.1-98.5)$ & $90(55.5-99.7)$ & $88.9(51.8-99.7)$ \\
Admission to outpatient surgery $(\%, 95 \% \mathrm{CI})$ & $95.4(92.3-97.5)$ & $100(69.2-100)$ & $88.9(51.8-99.7)$ \\
Duration (min, mean $\pm \mathrm{SD}, 95 \% \mathrm{CI})$ & $17.79 \pm 9.8(16.6-18.9)$ & $25 \pm 13.7(15.2-34.8)$ & $20.56 \pm 9.8(13-28.1)$ \\
Glycine loss $(\mathrm{ml}$, mean $\pm \mathrm{SD}, 95 \% \mathrm{CI})$ & $179.5 \pm 270.8(148-211)$ & $345 \pm 356.3(90.1-600$ & $289 \pm 301.8(57-521)$ \\
Complications $\quad$ No complications $(\%, 95 \% \mathrm{CI})$ & $97.2(94.5-98.8)$ & $100(69.2-100)$ & $100(66.4-100)$ \\
$\quad$ Hemorrhage $(\%, 95 \% \mathrm{CI})$ & $0.7(0.07-2.5)$ & - & - \\
$\quad$ Cervix tear $(\%, 95 \% \mathrm{CI})$ & $1.1(0.2-3.06)$ & - & - \\
$\quad$ Uterine perforation $(\%, 95 \% \mathrm{CI})$ & $1.1(0.2-3.06)$ & - & - \\
\hline
\end{tabular}

Duration: $P=0.062$ N.S. Glycine: $P=0.095$ N.S.

and the pulsability index concluded that nothing can substitute for polyp extraction and its anatomopathological study [15].

If the polyps cause metrorrhagia or menorrhagia, resecting them has proved to be effective and has significantly reduced the number of days and the amount of bleeding per month, as evaluated with a menorrhagia score [8]. The data for this study and other published studies suggest that in women with AUB who have endometrial polyps, the polyps are the cause of the bleeding in the majority of cases. Therefore, the polyp should be removed before less effective options are taken, such as uterine curettage or medical treatment, or more aggressive therapeutic options such as a hysterectomy.

The technique used to resect endometrial polyps may be with small instruments, in which case it is usually accomplished in an office, or with a resectoscope, which requires general or locoregional anesthesia, and therefore it is performed in an operating room, with a few hours in hospital.

In the office option, 5 Fr or 7 Fr scissors were usually used to resect the polyps. This technique has proved to correct AUB in premenopausal women [16]. Some authors use $5 \mathrm{Fr}$ bipolar electrodes without anesthesia, resecting polyps up to $4.5 \mathrm{~cm}$ in their offices. No relapses were observed in the follow-up of these patients [17].

In our study, out of 303 patients with endometrial polyps observed by office hysteroscopy, 10 hyperplasias with atypias and 9 endometrial cancers were found. This represents 3.3 and $3 \%$, respectively. The data are comparable to other series such as Bakour's, who described 3.2\% malignancies [3]; Goldstein 5\% [15]; Savelli, in a series of 509 resected polyps, described 3.1\% hyperplasia with atypia and $0.8 \%$ carcinoma [18]; and Lavie, in 864 endometrial polyps, identified $2.31 \%$ with endometrial carcinoma and $1.73 \%$ atypical hyperplasia [19]. Ben-Arie has similar data of premalignant or malignant changes in endometrial polyps, 3.3 and $3.0 \%$. He concluded that older age, menopausal status, and polyps larger than $1.5 \mathrm{~cm}$ were associated with significant premalignant or malignant changes. [20]

We performed an office polyp biopsy on all our patients, and in all cases the result was negative, even when a malignant lesion was later found in the polyp. These data confirm that the resection of a polyp fragment cannot exclude the existence of a more serious lesion at a different location. Other authors agree on the relative value of a hysteroscopy and of directed biopsy to rule out a carcinoma [21]. The conclusion is that it is necessary to resect the entire polyp and that a biopsy is insufficient to have a definitive diagnosis.

A hysterectomy with lymphadenectomy was performed in all cases of endometrial cancer, with the end diagnosis being FIGO stage I. These data support the fact that a falsenegative diagnosis was not made at the time of the office hysteroscopy. Likewise, it is not very probable that the time elapsed between office observation of the polyp and resection, 2-4 months, would have allowed a malignant lesion to develop. Although some authors have shown that up to $50 \%$ of small endometrial polyps may disappear [4], our results allow us to defend the theory that it is necessary to resect the polyps to be able to dismiss the existence of a malignant or premalignant lesion. Likewise, with this procedure we lessen the probability of abnormal uterine hemorrhage due to the polyp.

Hysteroscopic polypectomy is a technique with few complications, except for pain, when accomplished in an outpatient office. When performed in an operating room with a resectoscope, our data show that it is a simple technique, that it can be performed with regional anesthesia, and the patient will only be a few hours in hospital. In our study, complications were few and unimportant. There were three cases of cervical tears that required sutures for reconstruction or to prevent bleeding, two cases of bleeding that were stopped by blocking the uterine cavity with an intrauterine Foley 
catheter for a few hours, and three cases of uterine perforation without damage to adjacent structures.

In most cases, the main reason the women were referred to our unit was abnormal uterine bleeding. In the patients whose final diagnosis was hyperplasia with atypias or endometrial cancer, the most frequent reason for a hysteroscopic study was changes observed in the vaginal ultrasonography, 40 and $33.3 \%$, respectively, as opposed to $17.3 \%$ of benign polyps. We find that the larger size of malignant or premalignant lesions facilitates detection by ultrasonography.

\section{Conclusions}

The results of our study of 303 patients with endometrial polyps show a frequency of hyperplasia with atypias of $3.3 \%$ and of endometrial cancer of 3\% after a histological study of the polyps extracted by resectoscopy. Our data suggest that the image of polyps observed in office hysteroscopy is insufficient to rule out malignancy. Therefore, we recommend extraction of large and widely spread polyps by hysteroscopy with a resector for an anatomopathological study.

This technique can be accomplished with regional anesthesia. The patient does not require admission, and the complication rate is low or of little importance.

\section{References}

1. Ceci O, Bettochi S, Pellegrino A, Impedovo L, Di Venere R, Pansini N (2002) Comparison of hysteroscopic and hysterectomy findings for assesing the diagnostic accuracy of office hysteroscopy. Fertil Steril 78:628-631

2. Armenia CS (1967) Sequential relationship between endometrial polyps and carcinoma of the endometrium. Obstet Gynecol 30:524-529

3. Bakour SH, Khan KS, Gupta JK (2000) The risk of premalignant and malignant pathology in endometrial polyps. Acta Obstet Gynecol Scand 79:317-320

4. De Waay DL, Syrop CH, Nygaard IE, Davis WA, Van Boorhis BJ (2002) Natural history of uterine polyps and leiomyomata. Obstet Gynecol 100:3-7

5. Clark TJ, Khan KS, Gupta JK (2002) Current practice for the treatment of benign intrauterine polyps: a national questionnaire survey of consultan gynaecologists in UK. Eur J Obstet Gynecol Reprod Biol 103:65-67
6. Gebauer G, Hafner A, Siebzehnrubl E, Lang N (2001) Role of hysteroscopy in detection and extraction of endometrial polyps: results of a prospective study. Am J Obstet Gynecol 184:59-63

7. Cravello L, Stolla V, Bretelle F, Roger V, Blanc B (2000) Hysteroscopic resection of endometrial polyps: a study of 195 cases. Eur J Obstet Gynecol Reprod Biol 93:131-134

8. Tjarks M, Van Voorhis BJ (2000) Treatment of endometrial polyps. Obstet Gynecol 96:886-889

9. Andía D, Lafuente P, Matorras R, Usandizaga JM (2000) Uterine side effects of treatment with tamoxifen. Eur J Obstet Gynecol Reprod Biol 92:235-240

10. Pérez-Medina T, Bajo-Arenas J, Haya J, Sanfrutos L, Iniesta S, Bueno B, Castelo-Branco C (2003) Tibolone and risk of endometrial polyps: a prospective, comparative study with hormone therapy. Menopause 10:534-537

11. Kim MR, Kim YA, Jo MY, Hwang KY, Ryu HS (2003) High frequency of endometrial polyps in endometriosis. J Am Assoc Gynecol Laparosc 10:46-48

12. Pérez-Medina T, Martinez O, Folgueira G, Bajo J (1999) Which endometrial polyps should be resected? J Am Assoc Gynecol Laparosc 6:71-74

13. Pérez-Medina T, Bajo J, Huertas MA, Rubio A (2002) Predicting atypia inside endometrial polyps. J Ultrasound Med 21:125-128

14. Shushan A, Revel A, Rojansky N (2004) How often are endometrial polyps malignant? Gynecol Obstet Invest 58:212215

15. Goldstein SR, Monteagudo A, Popiolek D, Mayberry P, TimorTritsch I (2002) Evaluation of endometrial polyps. Am J Obstet Gynecol 186:669-674

16. Lure M, Marín A, Elorza A, Ezenarro E, Gorostidi M, Belar M, Rivero B (2000) Resección de pólipos por histeroscopia en mujeres con hemorragia uterina anormal. Clin Inves Gin Obst 27:263-265

17. Bettochi S, Ceci O, Di Venere R, Pansini MV, Pellegrino A, Marell F, Nappi L (2002) Advanced operative office hysteroscopy without anesthesia: analysis of 501 cases treated with a $5 \mathrm{Fr}$. bipolar electrode. Hum Reprod 17:2435-2438

18. Savelli L, De Iaco P, Santini D, Rosati F, Ghi T, Pignotti E, Bovicelli L (2003) Histopathologic features and risk factors for benignity, hyperplasia, and cancer in endometrial polyps. Am J Obstet Gynecol 188:927-931

19. Lavie O, Ben Arie A, Cohen S, Kedar R, Sagie S, Sharon A, Lissak A, Goldshmit H, Dgani R, Auslander R (2004) The risk of carcinoma and atypical hyperplasia in endometrial polyps. Int $\mathrm{J}$ Gynecol Cancer 14:139-140

20. Ben-Arie A, Goldchmit Ch, Laviv J, Levy R, Caspi B, Huszar M, Dgani R, Hagay Z (2004) The malignant potential of endometrial polyps. Eur J Obstet Gynecol Reprod Biol 115:206-210

21. De Wit AC, Vleuglels MP, De Kruif JH (2003) Diagnostic hysteroscopy: a valuable diagnostic tool in the diagnosis of structural intra-cavital pathology and endometrial hyperplasia or carcinoma? Six years of experience with non-clinical diagnostic hysteroscopy. Eur J Obstet Gynecol Reprod Biol 110:79-82 